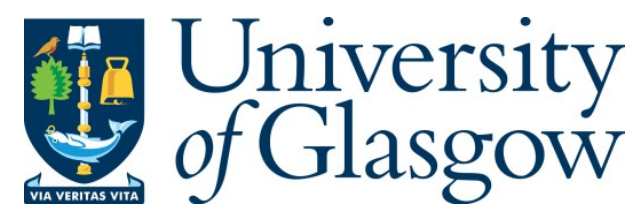

Lennard, Frances, and Dulieu-Barton, Janice M. (2014) Quantifying and visualising change: strain monitoring of tapestries with digital image

correlation. Studies in Conservation, 59 (4). pp. 241-255. ISSN 0039-3630

Copyright @ 2013 Maney Publishing

http://eprints.gla.ac.uk/66925/

Deposited on: 10 July 2012

Enlighten - Research publications by members of the University of Glasgow http://eprints.gla.ac.uk 


\title{
Quantifying and visualising change: Strain monitoring of tapestries with digital image correlation
}

\section{Frances Lennard}

\begin{abstract}
A three-year research project at the University of Southampton (2007-2010) investigated whether monitoring techniques commonly used by engineers to assess the strength and durability of materials could be usefully applied to inform the condition assessment of historic tapestries. To date it has not been possible to obtain an objective picture of the overall condition of a tapestry; the study investigated whether it is possible to identify precursors of structural damage. The two techniques, digital image correlation (DIC) and optical fibre sensors, were used to monitor a representative wool fabric, specially woven tapestry samples, a newly woven tapestry and historic tapestries, both in the laboratory and in situ in a historic house.
\end{abstract}

This paper first sets out to answer the question: can DIC be used to monitor and visualise strain in historic tapestries? It is shown that DIC can be used successfully. Secondly it discusses the map function, a novel development which allowed the monitoring equipment to be moved and so to be used in situ in a historic house. Thirdly it provides further detail of the experimental work using optical fibre sensors to confirm the accuracy of the DIC technique.

\section{Key words}

Tapestry, strain monitoring, digital image correlation, optical fibre sensors, strain map, map function, adhesives, polymer optical fibres

\section{Introduction}

A three-year research project at the University of Southampton (2007-2010) investigated whether monitoring techniques commonly used by engineers to assess the strength and durability of materials could be usefully applied to inform the condition assessment of historic tapestries. Textile conservators are experienced in visually assessing tapestries and chemical markers of deterioration have been identified (Vanden Berghe, 2012), but to date it has not been possible to obtain an objective picture of the overall condition of a tapestry, to inform interventive and preventive conservation treatments.

The research aimed to investigate whether it is possible to gain information invisible to the naked eye, i.e. to identify the precursors of future structural damage. Tapestries were used as a case study as they are large and heavy and it was assumed that damage is partially caused by their own weight. It is believed that this self-loading, combined with photochemical degradation, ultimately leads to tapestry 'failure', using the terminology of engineers. Although there is now a greater understanding of the degradation of tapestries at a molecular level (Zhang \& Wyeth, 2007), less is known about the physical deterioration mechanisms involved. The research reported in this paper focused on monitoring strain, defined as a measure of the permanent percentage deformation of a material, assuming that strain leads to damage. 
The research was carried out by an interdisciplinary team of two textile conservators, the author (the Principal Investigator) and Dr Dinah Eastop; and two engineers, Professor Janice Barton and Dr Alan Chambers, working with a team of a post-doctoral researcher, Dr ChenChun Ye and two PhD students, Djallal Khennouf and Helen Williams. The project was funded by the UK Arts and Humanities Research Council. ${ }^{1}$ An overview of the research was published in the proceedings of the ICOM Conservation Committee meeting in Lisbon in 2011 (Lennard et al., 2011). This paper provides a more detailed discussion of the experimental work and the results, to address the 'so what?' question for heritage conservation. It is written from the textile conservation perspective, aiming to providing a summary of the research, make it accessible to conservators and collection managers and focuss on what practising conservators would find useful. There is further information on the project website: http://www.tapestry-strain.org.uk

A pilot study had concluded that effective strain monitoring of textiles required a combination of a full-field measurement technique with reference sensors, with two techniques identified as particularly promising (Dulieu-Barton et al., 2005). These were firstly, a full-field, strain measurement technique based on 3D photogrammetry, known as digital image correlation (DIC); and secondly, point measurement of strain obtained via optical fibre sensors. These two techniques were trialled in the study reported here to monitor a representative wool fabric, specially woven tapestry samples, a newly woven tapestry and historic tapestries, both in the laboratory and in situ in a historic house.

DIC and optical fibre sensors are well-established monitoring techniques in the engineering field but their use on textiles presented several challenges. Tapestries deform markedly under load so the strains will be relatively large compared with those in 'engineering materials' such as reinforced steel, so it was necessary to determine whether the techniques could accurately monitor the strains. Tapestries are also very complex structures even compared with engineering materials such as composites: they are made up of different materials, usually wool and silk but also sometimes linen, cotton and metallic threads; the warp and weft yarns have different properties; and the weft yarns, from which the tapestry hangs, are discontinuous.

A key aim was to record differences in strain across a tapestry in order to provide detailed information about its condition. Tapestries deform significantly with changes in relative humidity as the fibres absorb and desorb moisture; separating the effects of relative humidity from the underlying permanent deformation caused by creep strain was an important aspect of the work. In addition, the strains in tapestries develop very slowly as they gradually deform over many years of display. DIC equipment had not previously been moved during monitoring, but it was clearly undesirable to have monitoring equipment continuously present in a historic house or museum for long periods. Rather the aim would be to bring equipment into the room periodically, making it necessary for the software to recognise individual areas of a tapestry. The development of a map function, enabling the monitoring equipment to be moved between images, was a major challenge and a notable outcome of the research.

Another key aim of the research was to provide data in a form that could be easily understood by conservators and curators in order to inform conservation decision-making. DIC data can be presented on colourful strain maps providing visual records of areas of high and low strain.

\section{Using DIC to monitor and visualise strain in historic tapestries}


DIC is a non-contact and non-destructive technique, making it particularly appropriate for monitoring historic objects. The DIC system used in the work (StrainMaster 3D DIC system, from LaVision $\mathrm{GmbH}$ ) used two white light high-resolution (2-megapixel) cameras to obtain images from the textiles under investigation. The software system (DaVis Version 7.2) brings the images from each camera together, providing information on 3D deformations in a map which acts as a reference for subsequent monitoring. As successive pairs of images are taken, the image correlation software records changes in strain as the object deforms. The resulting strain map shows areas of high strain in red shading to areas of low strain in blue, an excellent visual tool for conservators and curators, and for providing information to members of the public (Fig. 1).

The study began with a question: are tapestries being pulled apart by their own weight? Do tapestries experience creep strain, i.e.deformation caused by a constant stress applied to the material at certain temperature and humidity conditions over a long period of time? It was believed that the self-loading caused by their relatively large size and heavy weight could result in this type of permanent deformation.

Narrow tapestry weave panels were specially commissioned from West Dean Tapestry Studio for use in testing but their expense meant that initial investigation was carried out on a ribbed-weave wool textile with similar properties in the warp and weft yarns to a tapestry weave; e.g. the warp yarns were much more tightly twisted than the weft yarns. Tests were conducted by loading the specimens to cause deformation, using a standard Instron 5569 electromechanical test machine with a $2 \mathrm{kN}$ load cell. To avoid edge effects, the specimens were always at least $50 \mathrm{~mm}$ wide. Self-tightening grips were designed, consisting of a clamping mechanism with a roller, as it was recognised that the pressure of standard wedge grips could cause the textile to fail prematurely at the grips. The length of the specimens between the rollers was approximately $150 \mathrm{~mm}$.

Preliminary tensile test data confirmed that the warp and weft yarns of the ribbed-weave fabric behaved differently (Fig. 2). When the load was applied in the warp direction, the textile showed a behaviour that could be characterised as almost perfectly elastic-plastic with a region of nominally linear behaviour followed by a 'yield' and then 'plastic' behaviour followed by failure. When the load was applied in the weft direction the textile showed two regions of practically linear behaviour up to the maximum stress and then yarns started to break and failure occurred progressively. This clear difference in stress-strain behaviour in the two directions of the weave is attributed to the nature of the twist in the yarn. The highly twisted warp yarn unwinds in the 'plastic' region. The weft yarns, which are less twisted, display a 'brittle' fracture behaviour. Tapestries hang in the weft direction so the deformation under self-load is expected to follow the weft behaviour. The behaviour of the ribbed weave textile and that of a tapestry weave sample were compared. The weft direction behaviour in the two materials proved to be the same, validating the use of the ribbed weave textile for testing.

DIC is an optical technique that relies on adequate surface contrast for the computer vision algorithm to track the displacement of a deforming specimen; speckle paint patterns are commonly applied to test pieces to create sufficient contrast. Tests were carried out to 
determine whether the weave pattern of the ribbed-weave textile alone was sufficient for correlation. Stress-strain data from an unmarked specimen of ribbed-weave textile were compared with data from specimens marked with black dots of different sizes. There was a good match between the sets of data, showing that the single-coloured weave pattern alone can be used as the basis for image correlation. Although the weave structure appears regular to the human eye it contains sufficient irregularity for the cameras to resolve. The woven design of a tapestry contains even more information for camera recognition.

\section{Creep strain and effects of relative humidity [sub-heading]}

To establish the creep strain characteristics of the ribbed-weave textile material, a 48 hour long test was conducted on an $80 \mathrm{~mm}$ wide strip. During this period, a constant load of $40 \mathrm{~N}$ was applied to the specimen. One image was recorded every 5 minutes by each camera, while humidity and temperature were recorded at the same rate using a data logger with the sensor position approximately $20 \mathrm{~cm}$ away from the specimen. Figure 3 plots longitudinal strain measured by DIC, temperature and humidity versus time. Because the strain calculated by DIC was of the order of $0.2 \%$, in order to obtain acceptable accuracy, the plotted values were obtained by averaging strain from all the interrogation cells used, across the length and width of the specimen. This reduced the scatter in the data to $0.01 \%$, an acceptable figure.

When processing the DIC data to produce deformation and strain behaviour it is necessary to divide the image data into groups of pixels known as 'interrogation cells'. It was found that an interrogation cell size of $64 \times 64$ pixels ( 3 - 7 weft yarns) with no overlap gave a good compromise between strain resolution and spatial resolution. As the specimens were subjected to a uniform strain it was assumed that the local strain variation from interrogation cell to interrogation cell would be small. Therefore the interrogation cell size could be relatively large so as to maximise the strain resolution by averaging the figures across the cell - in other words, increasing the size of the data set ensured that the average figure was more reliable.

Following the 48 hour test shown in Figure 3, the plots were analysed to investigate the textile creep characteristics. It was noted that there was a very close relationship between temperature, relative humidity $(\mathrm{RH})$ and strain. In the first six hours of the test both $\mathrm{RH}$ and strain rose - the increase in strain was $150 \%$. After this initial period, $\mathrm{RH}$ gradually declined and there was a decline followed by a levelling off in strain. It is known that $\mathrm{RH}$ has an effect on the mechanical behaviour of textiles with wool fabric exhibiting increased stiffness as RH decreases (Morton \& Hearle, 1993). The decrease in $\mathrm{RH}$ during the test would increase the stiffness of the wool textile, leading to smaller deformations for the same load. This could explain the almost constant strain shown in the latter part of the test, as the change in $\mathrm{RH}$ counteracted any creep strain effects.

A custom woven tapestry panel was also monitored using DIC. In each test, the panel was subjected to a load cycle where a weight was added in increments of $0.5 \mathrm{~kg}$ up to a maximum of approximately $13 \mathrm{~kg}$ and then removed. At each load increment the panel was allowed to settle for a short period of time after which a set of images was captured, before the next weight was applied. Once the final weight had been applied, data were captured at regular intervals for a set period of time before unloading. The tapestry was then allowed to recover to its natural state before the application of the next loading cycle. The overall 
dimensions of the tapestry panel were recorded before and after each test. Table 1 shows the permanent lengthwise deformations after 14, 28, 56 and 84 days of exposure to load. After each time period it can be seen that the panel had been permanently extended. The prolonged application of the load caused dimensional changes in the panel. After removing the load from the panel and leaving it for a period of fourteen days, no recovery was apparent. The dimensional changes in the panel indicated that creep, or permanent deformation, had taken place (Williams et al., 2010). In addition, when observing a strain map derived from this tapestry panel, it was interesting to note that patches of higher and lower strain could be seen which appeared to coincide with discontinuities in the weft threads. This indicates that detail not necessarily apparent from the front of the tapestry could be detected by the DIC.

In order to further investigate the amount of strain tapestries undergo as a result of carrying their own weight a 48 hour test was carried out on an actual tapestry, a $17^{\text {th }}$ century Verdure fragment from the reference collection of the Textile Conservation Centre (TCC). The tapestry was made of wool warp yarns and wool and silk weft yarns and was lined with linen fabric; it was approximately $1.85 \mathrm{~m}$ wide and $1.65 \mathrm{~m}$ high and weighed approximately $5.8 \mathrm{~kg}$. The tapestry was hung from a Velcro® strip attached to its top edge as it would be on display. The test was conducted in the temperature and humidity controlled environment of the TCC to investigate further the relationship between $\mathrm{RH}$ and strain. DIC was used to monitor strain in a $120 \mathrm{~mm}$ by $90 \mathrm{~mm}$ area at the centre of the tapestry, and a digital temperature and humidity logger was used to monitor changes in temperature and $\mathrm{RH}$ during the experiment with one measurement every 5 minutes. As well as showing relative areas of high and low strain, the DIC provided quantitative measurements of the average strains across the area - these proved to be in the region of $0.1 \%$. Local strains are likely to be higher, but these data were more difficult to interpret as they contained more noise, i.e., a wider scatter of data points.

The obtained strain data were plotted against time as shown in Figure 4: the plot shows curves for $\mathrm{RH}$, temperature and longitudinal strain magnified 105 times (so that it can be shown on the same plot). In the controlled environment the temperature was maintained at a practically constant level. $\mathrm{RH}$ varied by only $8 \%$ but this small change had a very strong effect on the strain, a fluctuation of more than $0.06 \%$. As the moisture content of the air surrounding a tapestry changes, the tapestry responds rapidly to this change by altering its own moisture content to stay in equilibrium with the surrounding air. Howell (1996) recorded the weight of a tapestry, $\mathrm{RH}$, and temperature over a period of nine days, noticing a strong positive correlation between fluctuation in $\mathrm{RH}$ and the weight of the tapestry. The tapestry's weight dropped by around $1000 \mathrm{~g}$ from a starting point of approximately $43.3 \mathrm{~kg}$, over a period of 4 days. In the case of the Verdure tapestry it is assumed that as the moisture content of the tapestry increased, its increase in weight caused an increase in the strain recorded.

To provide a better indication of the effect of the $\mathrm{RH}$ change on the strain change, Figure 5 plots the $\mathrm{RH}$ against strain for all the values obtained for the plot in Figure 4. It can be observed that as the $\mathrm{RH}$ rises above $52 \%$ the tapestry experiences positive strain and as the $\mathrm{RH}$ falls below $52 \%$ the tapestry experiences negative strain (Khennouf et al., 2010). It is noteworthy that the relationship is practically linear, so it may be possible to correct for the changes in humidity and determine the creep strain rate. However, the cycling that is exhibited in Figure 4 is similar to a fatigue cycling and could potentially be more damaging 
than the creep as the friction between yarns will resist the extension or contraction. This mechanism may ultimately lead to degradation similar to the micro-movement associated with 'fretting fatigue' familiar to engineers.

To try to replicate this effect, accelerated strain cycling tests were carried out: the ribbedweave wool textile was subjected to cycles of increasing and decreasing strain at high frequency. The mechanical properties of the fabric were measured before and after loading, using quasi-static tests with the DIC to create stress-strain plots. Although this is not the same deterioration mechanism that would be caused by fluctuations in $\mathrm{RH}$ over a longer period, it was found that the repeated loading of the textile samples through 36,000 cycles caused the wool material to become more brittle, as shown in the stress-strain curve (Figure 6). The change is believed to be a result of the fibres lining up in the direction of the load and increasing crystallinity within the fibres. This appears to confirm that damage is caused to textiles by fluctuations in $\mathrm{RH}$. Similar research by a team from the Jagiellonian University and the National Museum in Krakow also found this response in a tapestry. However their work indicated that damage only occurred until 45,000 cycles were completed - at this point no further damage was noted (Bratasz, 2011).

A second test on the tapestry carried out over 130 hours demonstrated the repeatability of the results and confirmed that it is feasible to monitor the effect of humidity on strain in historic tapestries using DIC. In this test the transverse strains were also calculated and these also showed an increase in strain with increased humidity. The strong positive correlation between longitudinal strain and $\mathrm{RH}$ fluctuation can be seen more clearly in Figure 7 which plots strain in the longitudinal and transverse directions against $\mathrm{RH}$ in a scatter diagram for both the 48 hour and the 130 hour experiments. One of the main differences between the four plots is that they cross the $x$ axis in different points. As both experiments were carried out on the same part of the tapestry, it would be expected that the two longitudinal strain plots would cross the $x$ axis at the same point and the two transverse strain plots would cross the axis at the same point. The difference is explained by differences in $\mathrm{RH}$ during the test: a range of $49 \%-55 \% \mathrm{RH}$ during the 48 hour test compared with a fluctuation in the range of $45 \%-52 \%$ in the 130 hour test. However this did not have any significant effect on the slopes of the trend lines. In both experiments the two longitudinal strain scatter plots had a slope of 0.011 and the two transverse strain scatter plots had slopes of approximately 0.008 , clearly demonstrating the repeatability of such an approach.

A longer, 260 hour test on the Verdure tapestry was carried out in uncontrolled environmental conditions. The temperature during this period rose from $14^{\circ} \mathrm{C}$ to $18^{\circ} \mathrm{C}$ while $\mathrm{RH}$ fluctuated between $48 \%$ and $34 \%$. Figure 8 depicts the effect of the $\mathrm{RH}$ fluctuation on the longitudinal strain. The main observation from the graph is that the longitudinal strain remained well below $0.1 \%$ until the 85th hour of the test when $\mathrm{RH}$ started to decline at a faster rate. The longitudinal strain responded to this decrease reaching nearly $-0.7 \%$ near the end of the experiment. This strain level is one order of magnitude higher than the strain observed in the controlled humidity experiments. This indicates that displaying or storing tapestries in uncontrolled humidity environment may have significant effects on the rate of tapestry degradation.

When tests were carried out on different tapestries the plots showed a characteristic slope when strain was plotted in the longitudinal direction against $\mathrm{RH}$ in the transverse direction, 
indicating a unique response to changes in the environment in terms of the tapestry's material structure, eg the different proportions of wool and silk (Fig. 9). The slope for the Verdure tapestry was different in different tests; it appears that factors such as the $\mathrm{RH}$ range during the test, and whether the tapestry had been rolled or had already been hanging immediately before the test affected the strain behaviour. Tests carried out on a newly woven tapestry, custom made for the research project, showed a much greater increase in strain than the others. The new tapestry's weight per $\mathrm{m}^{2}$ is much greater than that of the historic tapestries, so it can absorb more moisture proportionally (Lennard, et al., 2011); the wool fibres are also relatively undamaged compared with those in historic tapestries, which also allows them to absorb more moisture.

The tests confirmed that DIC can be used to provide strain data from a discrete area of a tapestry. The final stage of monitoring took place in summer 2009 at Hardwick Hall, a National Trust property where the DIC equipment was installed temporarily in front of a 16th century Flemish tapestry (Fig. 10) providing an opportunity to disseminate information about the project to the public. The major challenge was to gather the data generated by the DIC from Hardwick, a property without a broadband signal. To cope with the large quantity of data generated, a continuous monitoring system was developed whereby each image was processed, then sent to a computer at the university via a temporary modem. The challenges of gathering the data remotely were successfully overcome, demonstrating that the DIC system could be used successfully on site, in a novel use of this technology which routinely uses fixed equipment.

\section{Map function}

In addition to the complex structure of tapestries, the research faced another major challenge: the long timescale involved in tapestry degradation. To conduct experiments over long periods of time, a new processing approach has been developed by the DIC manufacturer that allows correlation from data acquired using different camera set-ups. This allows the cameras to be moved between the acquisition of reference and deformed images, allowing periodic monitoring of tapestries. This 'map function' incorporates an additional processing stage allowing image pairs taken in the deformed state to be mapped onto image pairs taken in the reference state, so that the cameras can locate the same area of the tapestry. A pattern recognition algorithm was used to identify points of correspondence between the pairs of images (Khennouf, et al., 2010). The project team worked with the system manufacturer to refine the software controlling this function. One outcome was that the 2-megapixel CCD cameras were replaced with 5-megapixel cameras, improving the strain resolution. It was not possible to test the map function at Hardwick as the data processing and transfer from the 5-megapixel cameras was computationally expensive, and bandwidth for data transfer at Hardwick Hall was limited.

\section{Experimental work to validate DIC monitoring using optical fibre sensors}

Additional work aimed to validate strain data obtained from the DIC using optical fibre sensors. The pilot study had identified the potential of optical fibre sensors as a monitoring tool to validate the non-contact full-field DIC technique. Fibre Bragg Grating sensors (FBGs) were used in the research; these are inscribed in traditional silica (glass) optical fibres. A change in the wavelength of light passing through the deformed optical fibre sensor provides a measurement of the strain. This change was detected using a Swept Laser Interrogator 
(FBG-SLI) by Micron Optics. Initial tests were carried out on aluminium coupons using different types of strain monitoring sensor, an extensometer and strain gauges, as well as the FBGs. The results demonstrated that the DIC system was providing an accurate measurement of strain. Although there was a $9-10 \%$ deviation between the results obtained from the FBG and the other techniques, it was demonstrated that the measurements of strain from the FBGs could be successfully correlated against the other results.

\section{Adhesive attachment of optical fibres [sub-heading]}

Testing could now progress to the investigation of strain in new and historic tapestries, with measurements from the FBGs again being used to validate data from the DIC. It is not straightforward to monitor strain in textiles; commonly used strain measurement devices such as strain gauges are attached to the object to be monitored; in the case of a textile this causes local reinforcement, affecting the results. Optical fibres also have to be attached to the tapestries, and although they have only a small point of contact compared with strain gauges, there were still major challenges to be overcome in attaching them to a tapestry in order to give accurate strain measurement at the point of the sensor without the sensor itself causing reinforcement. Different attachment methods were trialled: stitching, bonding and weaving into a new tapestry. Early tests showed that stitching the optical fibre to a textile gave much less accurate results than bonding as the sensor was not in intimate enough contact with the substrate. An optical fibre containing two sensors was woven into a small tapestry specially commissioned from West Dean Tapestry Studio as the tapestry was created. During monitoring it was found that only one of the sensors worked and it was not able to transfer the strain as accurately as those in optical fibres bonded to the tapestry (Dulieu-Barton et al.,2007).

Therefore an important component of the research was to identify a suitable adhesive for bonding the optical fibres to textiles. It was necessary to investigate the interfacial interactions of the optical fibre, the textile material and the adhesive to establish firstly, whether the optical fibre attachment caused excessive reinforcement of the textile and secondly, whether the strain was accurately transferred to the sensor. A range of adhesives was tested, ultimately focusing on two types: a PVA 'conservation adhesive' (Mowilith DMC2) and a two-part epoxy adhesive (Araldite 2015). Initial tests were carried out on the ribbed-weave wool textile.

In order to assess the possible reinforcing effects of the optical fibre and the two adhesives on the textile, FBGs were bonded with the two types of adhesive to textile specimens. They were mounted in an Instron 5569 test machine using wedge grips, with a distance between the grips of $250 \mathrm{~mm}$, and loaded under a constant displacement of $15 \mathrm{~mm} /$ minute until the applied load reached $30 \mathrm{~N}$. DIC data were collected simultaneously with the data from the FBG sensors. The DIC provided readings from the textile material both at the point of and remote from the FBGs.

A typical DIC strain map of the specimen with the Araldite adhesive (Fig. 11) clearly shows that the strain is much smaller in the area where the FBG is bonded, compared with that elsewhere in the specimen. This confirmed the reinforcing effect of bonding the optical fibre. This effect was greater when using Araldite than with the Mowilith. The difference in reinforcement can be explained by calculating the Young's modulus and cross section area of the combined adhesive, silica fibre and the textile covered with adhesive. This value is 
approximately three times greater for the specimen with Araldite compared with those of the Mowilith (Ye et al., 2009a).

The tests also investigated whether the strain was accurately transferred to the sensor. They demonstrated that the strain transfer coefficient was very low, ie the strain readings from the FBGs were much smaller than the true strain values, showing that the strain was not being adequately transferred though either adhesive into the optical fibre. The strain transfer coefficient was greater for the specimen with Araldite than that given by the Mowilith, but it was much lower than would be expected when bonding the optical fibre to an 'engineering material'. One possible explanation is that the textile is not a homogenous material. Its uneven surface may prevent a perfect bond between the optical fibre and the substrate, leading to a reduction in the strain transfer coefficient. Although it was found that strain readings from the FBG sensor were smaller than the true strain values in the textiles, the readings could be used as a reference measurement for the DIC if the FBG readings were correlated against those from the DIC (Ye, et al., 2009a).

Polymer optical fibres [sub-heading]

It was clearly desirable to obtain a better compatibility between the stiffness of the optical fibre, the adhesive and the textile to reduce the reinforcement introduced by the sensor attachment. Tests were therefore conducted using plastic optical fibres (POFs) in what was, to the researchers' knowledge, the first application of POF FBG technology outside the field of optics. The POFs were photoinscribed at Aston University. Plastic optical fibres offer significant advantages for application to textiles. The Young's modulus of polymethylmethacrylate (PMMA) POF is approximately 25 times smaller that of a silica fibre, thus much more compatible with the modulus of wool, and POFS can withstand and measure much higher strains than a silica fibre. Oddy tests on both types of optical fibre showed that both were safe to use in contact with historic textiles.

Tests were carried out to compare polymer and silica optical fibres. Both polymer and silica fibres were bonded to the textile surface with Araldite 2015, with another pair of polymer and silica fibres bonded with Mowilith DMC2. For each FBG, the area covered with adhesive was $3 \mathrm{~mm}$ wide, and up to $50 \mathrm{~mm}$ long. The thickness of adhesive was up to $0.4 \mathrm{~mm}$. The specimen was mounted in the Instron test machine with a distance between the grips of 240 $\mathrm{mm}$. The DIC system was used with a single camera to monitor the strain over the entire specimen. Data were also collected from an area of the specimen without adhesives, to maximise the strain accuracy of DIC by eliminating any possible effects of adhesives on the image correlation processing. The size of the interrogation window was chosen to be $32 \times 32$ pixels, corresponding to $3 \times 3 \mathrm{~mm}$ in the specimen.

In the first test a maximum load of $22 \mathrm{~N}$ was applied to the specimen to provide the strain map shown in Figure 12. The strain values in the two areas covered by Araldite were significantly lower than in the rest of the sample, indicating that this adhesive caused significant reinforcement of the textile. The strain in the area where a silica fibre was bonded with Mowilith was also lower than the surrounding areas, but the strain in the area of the polymer fibre bonded with Mowilith is closer to that of the background material.

In Figure 13 the recorded stress is plotted against the strains from the different FBGs and from DIC for different locations. The stress is the total load divided by the area of cross 
section of the textile specimen. The strain from the polymer FBG is greater than that from the silica FBG with the same adhesive. The recorded strain from each type of FBG with Mowilith is greater than that with Araldite, showing that the Mowilith underwent greater extension and did not reinforce the textile to the same degree as the Araldite. However it was not possible to record strain data from the polymer FBG when the stress was greater than 0.4 MPa since the maximum wavelength of the interrogation system was exceeded. The strains from the two polymer FBGs match the corresponding strains from DIC, although the one bonded using the epoxy adhesive shows much more scatter. The strains from DIC for the areas where the two silica FBGs were bonded are noisy (i.e. show more scatter), and even became negative when the load was small, indicating the unreliability of the DIC data in this area with strains smaller than $0.2 \%$. Successive tests showed that the repeatability of the results was good. From the strain data it is possible to calculate the reinforcement coefficients, which are given in Table 2. The reinforcement coefficient is the ratio of strain measured by the DIC local to the sensor to that away from the sensor - when there is no reinforcement this figure is 1 .

The table also gives the strain transfer coefficients: the ratio of the strain measured by the FBGs divided by the strain measured by the DIC - a measure of the accuracy of the strain data in the area around the sensor. Ideally the strain transfer coefficient should be close to 1 and this is the case for the polymer optical fibres. However it is not the case for the silica fibres. The uncertainty in the strain measured by the DIC in the area surrounding the silica FBGs is a key consideration (Ye et al., 2009b). A theoretical value for the strain transfer coefficient using an analytical model (Li et al., 2006) is very close to the actual values for the polymer fibres but there is a large discrepancy in the silica fibre FBGs indicating that errors in the DIC are the cause. In these tests the strains for the areas with silica FBGs bonded were too small to be measured by this DIC system.

In conclusion the tests showed that polymer optical fibres provided a favourable strain transfer coefficient compared with silica optical fibres, i.e. that polymer fibres were able to provide a more accurate measurement of strain. They also showed that the polymer fibres bonded with Mowilith offered less structural reinforcement. (Ye et al., 2009b). However longer term tests on the polymer optical fibres showed that the strain transfer decreased gradually for the FBG bonded with Mowilith over a 24 hour period, but that Araldite offered stable strain transfer between the textile and optical fibre. In addition the polymer FBG adhered with Araldite was virtually unaffected by increasing $\mathrm{RH}$ while the polymer FBG with PVA was slightly more sensitive. These results could be used to develop $\mathrm{RH}$ compensation techniques so that it would be possible to separate the effects of $\mathrm{RH}$ from those of creep strain over a longer time period.

\section{Discussion}

The project aimed to enhance the long-term preservation of tapestries by developing wellestablished engineering techniques to monitor the strain behaviour of tapestries, simply and unobtrusively, in-situ. The testing programme demonstrated that strain data could be successfully obtained from textile specimens using DIC, providing an objective and quantifiable measurement of tapestry condition through identifying areas of high strain, presumed to be a precursor of damage. As well as showing relative areas of high and low strain, the DIC provided quantitative measurements of the average strains across an area of a tapestry, although it was not possible at this stage to monitor a tapestry in its entirety. The 
data were confirmed by results from other strain measurement techniques, including optical fibre sensors. The project also successfully implemented the map function which allowed the DIC equipment to be employed periodically, making in situ monitoring achievable in practice. In addition DIC creates colourful strain maps which can be overlaid on images of a tapestry making it a very useful tool for conservators, curators and other stakeholders to visualise and assess the relative strain in different areas of a tapestry and so to inform conservation decision-making. It is hoped that future work at the University of Glasgow will apply these monitoring techniques to give an objective assessment of the effects of different conservation and lining methods on the tapestry structure. They could also be used to monitor objects made from other materials.

These monitoring experiments indicate that although tapestries are viewed by engineers as complex structures, it is possible to approximate their strain response to $\mathrm{RH}$ changes using a linear mathematical model. The data generated from this work could be used to construct empirical mathematical models for predicting the behaviour of tapestries in various $\mathrm{RH}$ conditions. It is accepted that to create the ideal modeling tool a larger data set would be required and indeed a reliable model would be the result of an iterative process. However, the results produced from this work demonstrate how accurate data can be collected which can, in turn, be used to create a computational model to predict mechanical damage of tapestries. This would result in a step change in the current understanding of the condition of historic tapestries.

Such models could be used to inform the long term effect of strain changes resulting from humidity fluctuations and hence the most appropriate level of $\mathrm{RH}$ for display, a key issue at a time when the parameters for environmental control are under review. Another conclusion from the work is that optical fibre sensors are an easy-to-install strain measurement technique requiring very little equipment. It could be possible to use them routinely for continuous strain measurement of tapestries and other artefacts. Although polymer optical fibres sensors are not yet commercially available, the use of POFs is clearly advantageous for monitoring textiles.

\section{Conclusion}

The use of strain monitoring techniques can contribute to our understanding of the mechanisms causing damage to historic tapestries and to other organic materials. The research set out to investigate whether the permanent deformation caused by creep strain is a significant factor in tapestry deterioration, whether tapestries are in effect being pulled apart by their own weight. Although evidence of permanent deformation was found, longer terms tests will be necessary to gain more information, but, perhaps unsurprisingly, it was found that the constant expansion and contraction of the material caused by fluctuations in relative humidity is likely to be even more damaging. There is clearly a complex relationship between creep strain and fatigue as increasing $\mathrm{RH}$ causes an increase in weight but also a decrease in stiffness and so a decreased resistance to deformation.

\section{6 words}

\section{Acknowledgements}

The author acknowledges the work of all members of the project team (see note 1). The team was supported by members of the project Advisory Panel: Dr Paul Garside, Textile 
Conservation Centre (now at the British Library); Dr Kathryn Hallett, Historic Royal Palaces; David Hollis, LaVision; Ksynia Marko, The National Trust; David Thickett, English Heritage; Dr David Webb, University of Aston; Dr Christina Young, Courtauld Institute of Art. The team was also grateful to Nigel Wright, Property Manager at Hardwick Hall, the National Trust; Caron Penney, Head of the Tapestry Studio and the tapestry weavers at West Dean Tapestry Studio; Andy Lane, Marketing Manager, Intech, Winchester. The Institute of Physics supported the display at Intech.

\section{Notes}

1 AHRC Research Grant award AH/D001404/1, £386,000. Principal Investigator: Frances Lennard. Co-investigators: Professor Janice Dulieu-Barton, Dr Alan Chambers. Team member: Dr Dinah Eastop. Post-doctoral researcher: Dr Chen-Chun Ye. PhD students: Djallal Khennouf (PhD awarded 2010), Helen Williams.

\section{List of suppliers}

StrainMaster 3D DIC system, LaVision GmbH http://www.lavision.de/en/ Swept Laser Interrogator (FBG-SLI), Micron Optics http://www.micronoptics.com/

\section{References}

Bratasz, L. ed. 2011. Preservation of Historic Textiles. Research project of the European Economic Area Financial Mechanism: Direct Monitoring of Strain for Protection of Historic Textiles and Paintings on Canvas. Krakow: The Laboratory of Analysis and Non-destructive Testing of Artefacts, The National Museum in Krakow.

Dulieu-Barton, J.M., Dokos, L., Eastop, D. E., Lennard, F. J., Chambers, A.R. \& Sahin, M. 2005. Deformation and Strain Measurement Techniques for the Inspection of Damage in Works of Art. Reviews in Conservation, 6: 61-71.

Dulieu-Barton, J.M., Sahin, M., Lennard, F. J., Eastop, D. E. \& Chambers, A.R. 2007. Assessing the Feasibility of Monitoring the Condition of Historic Tapestries using Engineering Techniques. Key Engineering Materials, 347: 187-192.

Howell, D. 1996. Some Mechanical Effects of Inappropriate Humidity on Textiles. In: J. Bridgland, ed. ICOM Committee for Conservation, $11^{\text {th }}$ Triennial Meeting, Preprints. London: James and James, vol. II, pp. 692-8.

Khennouf, D., Dulieu-Barton, J.M., Chambers, A.R., Lennard, F.J. and Eastop, D.E.. 2010. Assessing the Feasibility of Monitoring Strain in Historical Tapestries using Digital Image Correlation. Strain, 46, 19-32. DOI: 10.1111/j.1475-1305.2009.00637.x

Lennard, F., Eastop, D., Dulieu-Barton, J., Chambers, A., Khennouf, D., Ye, C.C. \& Williams, H. 2011. Strain Monitoring of Tapestries: Results of a Three-year Research Project. In: J. Bridgland, ed. ICOM Committee for Conservation, $16^{\text {th }}$ Triennial Meeting, Preprints. Cd rom format. $8 \mathrm{pp}$.

Li D., Li H., Ren L., Song G. 2006. Strain Transferring Analysis of Fiber Bragg Grating Sensors. Optical Engineering, 45 (2): 024402-1-8. 
Morton, W.E. \& Hearle, J.W.S. 1993. Physical Properties of Textile Fibres. Manchester: Manchester Textile Institute.

Vanden Berghe, I. 2012. Towards an Early Warning System for Oxidative Degradation of Polymer Fibres in Historical Tapestries by Means of Calibrated Amino Acid Analysis. Journal of Archaeological Science, 39: 1349-1359.

Williams, H. R., Lennard, F., Eastop, D., Dulieu-Barton, J. M. \& Chambers, A. R. 2010. Application of Digital Image Correlation to Tapestry \& Textile Condition Assessment. In J. Thompson, ed. Proceedings of AIC Textile Specialty Group, Los Angeles, May 2009. Washington D.C.: AIC: pp.156-170. Cd rom format.

Ye, C.C., Dulieu-Barton, J.M., Chambers, A.R., Lennard, F.J. \& Eastop, D.E. 2009a. Condition Monitoring of Textiles using Optical Techniques. Key Engineering Materials, 413-414: 447-454.

Ye, C.C., Dulieu-Barton, J.M., Webb, D.J., Zhang, C., Peng, G.-D., Chambers, A.R. Lennard, F.J. \& D.D.Eastop. 2009b. Applications of Polymer Optical Fibre Grating Sensors to Condition Monitoring of Textiles. In J. Jones, B. Culshaw, W. Ecke, J. M. López-Higuera \& R. Willsch, eds. 20th International Conference on Optical Fibre Sensors, Proceedings of SPIE Vol. 7503, 75030M: pp. 0M1-0M4.

Zhang, X. \& Wyeth, P. 2007. Moisture Sorption as a Potential Condition Marker for Historic Silks: Noninvasive Determination by Near-infrared Spectroscopy. Applied Spectroscopy 61, (2): 218-222.

\section{Captions}

Fig. 1 The DIC software produces colourful strain maps, showing areas of high strain in red shading to areas of low strain in blue, which can be overlaid on images of a tapestry.

Fig. 2 The plot shows the different behaviour of warp and weft yarns. The warp yarn of the ribbed weave textile shows a region of elastic behaviour followed by a 'yield' and then plastic behaviour followed by failure. The weft yarns of tapestry weave and ribbed weave textiles are more brittle. They show two regions of practically linear behaviour up to maximum stress when yarns start to break causing progressive failure.

Fig. 3 The plot shows a close relationship between temperature, $\mathrm{RH}$ and strain.

Fig. 4 In a test on a Verdure tapestry, a small change in RH over a 24 hour cycle had a strong effect on the strain. (The 20 mark on the y axis corresponds to $20 \% \mathrm{RH}, 20^{\circ} \mathrm{C}$ and $0.02 \%$ strain.)

Fig. 5 Here the strain values obtained for the plot in Fig. 4 are plotted against $\mathrm{RH}$. As the $\mathrm{RH}$ rises above $52 \%$ the tapestry experiences positive strain and as the $\mathrm{RH}$ falls below $52 \%$ the tapestry experiences negative strain.

Fig. 6 The change in the stress-strain curve shows that the textile sample has become more brittle after repeated loading through 36,000 cycles. 
Fig. 7 The strong positive correlation between longitudinal strain and RH fluctuation can be seen in this plot recording the strain in both longitudinal and transverse directions for the 48 hour and 130 hour experiments on the Verdure tapestry.

Fig. 8 The plot shows the effect of the RH fluctuation on longitudinal strain when the tapestry was hung in uncontrolled conditions: the strain level is one order of magnitude higher than the strain observed in controlled humidity experiments. (Strain has been scaled by 104 times so that it can be plotted with $\mathrm{RH}$. Therefore the 20 mark on refers to $20 \% \mathrm{RH}$ and $0.2 \%$ strain.)

Fig. 9 Tests carried out on different tapestries showed characteristic slopes for each test when plotting strain against $\mathrm{RH}$, indicating that each tapestry has a unique response to environmental changes. The different slopes for successive tests on the Verdure tapestry can be explained by e.g. differing $\mathrm{RH}$ conditions for each test.

Fig. 10 Using DIC to monitor a $16^{\text {th }}$ century Flemish tapestry at Hardwick Hall, a National Trust property.

Fig. 11 A typical DIC strain map of the specimen with Araldite adhesive. The strain is much smaller in the area where the FBG is bonded, showing the reinforcing effect of bonding the silica optical fibre.

Fig. 12 The strain in the areas covered by Araldite are significantly lower than in the rest of the specimen, showing that the adhesive caused significant reinforcement of the textile. The strain in the area of the polymer fibre bonded with Mowilith is closer to that of the background material.

Fig. 13 Stress plotted against the strains measured by the FBGs and the DIC for different locations. The strains from the two polymer FBGs match the corresponding strains from DIC.

Table 1 The table shows the permanent lengthwise deformation in the tapestry woven panel after 14, 28, 56 and 84 days of exposure to load.

Table 2 Strain transfer coefficient and reinforcement coefficient values for polymer and silica optical fibres, derived from the strain data shown in Fig. 12.

\section{Biography}

Frances Lennard gained the Postgraduate Diploma in Textile Conservation from the Textile Conservation Centre (TCC) and the Courtauld Institute of Art in 1982. She worked as a textile conservator for 15 years, for the TCC and in partnership with Fiona Hutton in the south-west of England, before returning to the TCC at the University of Southampton in 2001 where she became Programme Leader of the MA Textile Conservation. She now leads the MPhil Textile Conservation at the University of Glasgow. Her research interests are in the conservation treatment of textiles, particularly tapestries and painted banners. She is coeditor of Tapestry Conservation: Principles and Practice (with Maria Hayward, Elsevier, 2006) and of Textile Conservation: Advances in Practice (with Patricia Ewer, Elsevier, 2010).

\section{Frances Lennard}

Senior Lecturer, Textile Conservation 
Centre for Textile Conservation and Technical Art History

University of Glasgow

8 University Gardens

Glasgow G12 8QH

Frances.Lennard@glasgow.ac.uk 